\title{
Genomic Constitution and Expression of Disease Resistance in Agropyron cristatum $\times$ Durum Wheat Derivatives
}

\author{
Mahmoud Hamed Soliman ${ }^{1,2)}$, Adoración Cabrera ${ }^{2)}$, Josefina Carmen Sillero ${ }^{3)}$ and Diego Rubiales ${ }^{* 1)}$ \\ 1) Department of Plant Breeding, Institute of Sustainable Agriculture, CSIC, Apdo. 14080, Córdoba, Spain \\ 2) Department of Genetics, ETSIAM, University of Córdoba, Edificio Mendel, Campus Rabanales, Córdoba, Spain \\ 3) CIFA Alameda del Obispo, IFAPA-CICE, Apdo. 3092, E-14080 Córdoba, Spain
}

\begin{abstract}
Septoria leaf blotch, powdery mildew and yellow and brown rusts are major wheat diseases characterized by a worldwide distribution. The level of genetic resistance against these diseases is low in durum wheat (Triticum turgidum) germplasm, while some wheat relatives, such as crested wheatgrass (Agropyron cristatum), are resistant. In an attempt to incorporate resistance genes into durum wheat, crosses were carried out between durum wheat and a fertile allotetraploid $(2 \mathrm{n}=4 \mathrm{x}=28$; DDPP) previously obtained from a cross between diploid wheat (T. tauschii) and crested wheatgrass (A. cristatum). The plants were backcrossed twice to durum wheat and studied for their reaction to the diseases. The genomic constitution of all the backcross derivatives from these crosses were analyzed by fluorescence in situ hybridization (FISH) using both total genomic DNA of A. cristatum and the pAs1 repetitive DNA sequence isolated from T. tauschii. All of them retained chromosomes or chromosome segments of $A$. cristatum. All the analyzed plants were immune to septoria leaf blotch and powdery mildew and showed a high level of resistance to yellow and brown rusts.
\end{abstract}

Key Words: wheat, Agropyron, resistance, intergeneric hybridization, rust, septoria, powdery mildew.

\section{Introduction}

Durum wheat production is severely affected by a number of diseases, of which powdery mildew (Blumeria graminis f.sp. tritici), yellow rust (Puccinia striiformis f.sp. tritici), brown rust (P. triticina) and septoria leaf blotch (Mycosphaerella graminicola, anamorph Septoria tritici) are particularly important and exhibit a worldwide distribution.

Powdery mildew and rusts cause considerable yield losses in many areas. Although a number of $P m$ genes for resistance to powdery mildew, $L r$ genes for leaf rust resistance and $Y r$ genes for yellow rust resistance have been identified (McIntosh et al. 1998), most of these genes were detected in bread wheat and almost all of these resistance genes introgressed into bread commercial cultivars have become ineffective due to the occurrence of new virulent strains of the pathogen. Limited progress has been achieved in the identification of resistance to these pathogens in durum wheat. Therefore, screening of potentially new sources of genetic resistance and the combination of more than one resistance gene would be important to widen the gene pool of durum wheat.

Septoria leaf blotch is economically significant in the Mediterranean region and in all the major wheat-growing

Communicated by Michael Banman

Received May 31, 2006. Accepted September 29, 2006.

*Corresponding author (e-mail: ge2ruozd@uco.es) temperate areas of the world (Scharen 1999). Compared to other wheat diseases, such as powdery mildew and rusts, progress in genetic analysis of resistance to septoria leaf blotch has been limited. Breeding for septoria leaf blotch disease resistance has lagged due to the scarcity of resistant germplasm and an inadequate understanding of hostpathogen relationships. In spite of recent achievements in the identification of resistance to septoria leaf blotch in bread wheat (Chartrain et al. 2004), limited progress has been achieved in the case of durum wheat (Yahyaoui et al. 2000).

Wheatgrasses (species of the Agropyron complex) are perennial species of economic importance as forages, all of them having the same basic genome designated as $\mathrm{P}$ (Dewey 1984). Additionally, Agropyron species have been found to display potentially valuable traits for wheat improvement, including those for disease resistance (Sharma et al. 1995), tolerance to drought (Asay and Johnson 1990) and low temperature (Limin and Fowler 1987). Some of these species have been used in wheat breeding programs aimed at incorporating resistance into this crop. Hybrids and amphiploids between Triticum ssp. and different Agropyron species have been obtained (Li and Dong 1990, 1991, Chen et al. 1989, 1992, Limin and Fowler 1990). However, success in hybridization with durum wheat has been limited. Only recently have amphiploids involving T. turgidum and the fertile allotetraploid $T$. tauschii-A. cristatum $(2 \mathrm{n}=4 \mathrm{x}=29$; DDPP) been obtained (Soliman et al. 2001).

In the present paper, the results obtained after the crossing with and backcrossing of these amphiploids to durum 
wheat, the identification by FISH of the retained alien A. cristatum chromosomes in the progenies and the determination of the effect of these chromosomes on diseases resistance were reported.

\section{Materials and Methods}

\section{Plant material}

The self-fertile amphiploid DDPP $(2 n=4 x=28)$, designated as $\times$ Agroticum, previously obtained by crossing tetraploid accessions of $A$. cristatum and T. tauschii (Martín et al. 1999), was crossed with durum wheat cv. Gerardo (T15) and the resulting amphiploid (T15 $\times$ DDPP, $2 \mathrm{n}=8 \mathrm{x}=56$, AABBDDPP) was backcrossed two times to different durum wheat parents (Table 1).

\section{Cytological analysis}

Seeds were germinated on moist filter paper for 24-48 $\mathrm{h}$ at $4^{\circ} \mathrm{C}$ and then for $72 \mathrm{~h}$ at $25^{\circ} \mathrm{C}$ in order to synchronize the cell divisions. The excised root tips were pretreated with $0.05 \%$ colchicine for about 3 hours at room temperature to accumulate metaphases, and then fixed in a mixture of $3: 1$ (v/v) 100\% ethanol : glacial acetic acid for 20 days. The root tips were then pre-treated for five minutes with $45 \%$ acetocarmine and the number of chromosomes was determined by examination of squash preparations in a drop of $45 \%$ acetic acid using a Nikon Labophot microscope (Soliman et al. 2001). The preparations were frozen in liquid nitrogen for one minute to remove the coverslips. The preparations were used immediately or kept refrigerated until use for in situ hybridization.

The fluorescence in situ hybridization (FISH) protocol was carried out, as reported by Cabrera et al. (1999). The number of $\mathrm{P}$ chromosomes or chromosome segments from A. cristatum was determined using total genomic DNA from A. cristatum. The repetitive pAs1 sequence, isolated from T. tauschii (Rayburn and Gill 1986) was used to determine the number of D-genome chromosomes. Mitotic chromosome preparations were hybridized simultaneously with both digoxigenin-labeled DNA from $A$. cristatum and a biotinlabeled pAs1 probe, respectively. No blocking DNA was needed to clearly discriminate these probes. The hybridization sites were detected using antidigoxigenin-FITC (fluorescein isothiocyanate Boehringer Mannheim) and streptavidinCy3 conjugate (Sigma, St. Louis, MO, USA) respectively. The chromosomes were counterstained with DAPI $\left(4^{\prime}, 6-\right.$ diamidino-2-phenylindole).

\section{Resistance screenings Septoria tritici}

Hybrid plants, together with the parental lines and cvs. Vitron and Tango were inoculated at the three- to four- leaf stages by spraying the leaves with a spore suspension of $10^{6}$ spores $/ \mathrm{ml}$ of a local isolate of $S$. tritici (Co-St-01). For every eighty $\mathrm{ml}$ of the spore suspension, one drop of a surfactant agent (Tween 20) was added. Plants were kept at room tem- perature until the leaves were dry, and then incubated for 48 hours in the dark at $20^{\circ} \mathrm{C}$ and $100 \%$ relative humidity (RH). The plants were then transferred to a growth chamber at $20^{\circ} \mathrm{C}$ under a $14 \mathrm{~h}$ photoperiod at 10,000 lux. Four replications of 5 plants each were performed for the susceptible checks and parental lines, but not for the hybrid plants due to the scarcity of plant material. Percentage of the leaf area covered with lesions in individual plants was assessed at 30 days after inoculation.

Yellow and brown rusts

The resistance to yellow and brown rust pathogens was evaluated under field conditions at the adult plant stage. Test plants were surrounded by rows of the susceptible bread wheat cvs. Morocco and Mahisa and durum wheat cvs. Vitron and Tango, that served as spreaders and susceptible checks. Infection was promoted by inoculation of spreader rows with a mixture of spores in talcum powder. Isolates used were Co-E16 of $P$. striiformis (virulent on $\operatorname{Yr} 6$ and 7) and Co-00 of P. triticinia (virulent on $\mathrm{Lr} 2 \mathrm{~b}, 2 \mathrm{c}, 14 a, 18,20$ and 23). Disease severity (DS) was recorded as the percentage of the leaf area covered with lesions at the heading stage. Powdery mildew

For the adult plant test, mildew infection occurred naturally under field conditions in Córdoba. Disease scores were based on the percentage of the leaf area covered with mildew at the adult plant stage. Test plants were surrounded by rows of cv. Vitron and Arcobaleno as checks.

Seedlings were analyzed in a detached leaf assay. Two central segments (about $2 \mathrm{~cm}$ ) of expanded fourth-formed leaves were excised from the hybrid plants and parental lines and placed in trays containing solid medium consisting of Water Agar Benzimidazol. Leaf segments were inoculated with fresh spores of $B$. graminis f.sp. tritici using a settling tower. The inoculum density was about 130 conidia $/ \mathrm{cm}^{2}$. The trays which were placed in a growth cabinet were incubated at $20^{\circ} \mathrm{C}$ and covered to ensure a high $\mathrm{RH}$. One leaf segment of each of the accessions was fixed for 24 hours after inoculation on pads moistened with ethanol acetic acid $(3: 1)$ and cleared with lactoglycerol, water, lactic acid and glycerin $(1: 1: 1)$. To stain the fungal structures and facilitate microscopy, the leaf segments were sprayed with Trypan blue in lactophenol-ethanol $(1: 2)$. Percentages of the spores that germinated were determined for 200 to 750 randomly selected conidia per leaf segment. The sporelings were classified according to their stage of development. We defined established colonies as individuals that formed at least a secondary hypha, indicative of haustorial functionality (Rubiales and Carver 2000). For the other leaf segment, the percentage of the leaf area covered with lesions for each individual segment was determined at 5 days after inoculation.

\section{Results and Discussion}

From a total of $29 \mathrm{BC}_{2}$ seeds obtained, seven adult plants were able to develop (Table 1). The total number of 
chromosomes in these hybrid plants ranged from $2 \mathrm{n}=32$ to $2 n=42$. Both chromosomal instability and irregularities at the meiosis which had been previously observed in the parental $\times$ Agroticum $($ DDPP) (Martín et al. 1999) and the durum wheat $\times$ DDPP amphiploid (T15 $\times$ DDPP) $($ Soliman et al. 2001 ) could account for the observed variation in the chromosome number.

FISH using both total genomic DNA from $A$. cristatum and repetitive DNA pAs1 sequence as probes, allowed for simultaneous discrimination of both $\mathrm{P}$ - and D-genome chromosomes derived from A. cristatum and T. tauschii, respectively in the $\mathrm{BC}_{2}$ plants. All the plants carried a number of chromosomes from A. cristatum, ranging from 2 to 7 . The number of D-genome chromosomes from $T$. tauschii ranged from 2 to 10 (Table 1). No intergenomic translocations between wheat and $A$. cristatum chromosomes were observed.

Table 1. Chromosome number and reaction to septoria leaf blotch, powdery mildew and yellow and brown rusts of durum wheat and Agropyron cristatum accessions, their amphiploids and backcrosses with durum wheat

\begin{tabular}{|c|c|c|c|c|c|c|c|c|c|c|}
\hline \multirow{3}{*}{ Species } & \multirow{3}{*}{ Lines } & \multirow{3}{*}{$\begin{array}{c}\text { Total } \\
\text { chromos. } \\
\text { number }\end{array}$} & \multirow{3}{*}{$\begin{array}{l}\text { No. of P } \\
\text { chromos. }\end{array}$} & \multirow{3}{*}{$\begin{array}{l}\text { No. of D } \\
\text { chromos. }\end{array}$} & \multicolumn{4}{|c|}{ Field trials } & \multicolumn{2}{|c|}{ Detached leaf assays } \\
\hline & & & & & \multicolumn{4}{|c|}{$\%$ leaf area covered with lesions } & $\begin{array}{c}\% \text { leaf area } \\
\text { covered with } \\
\text { colonies }\end{array}$ & $\begin{array}{c}\% \\
\text { established } \\
\text { colonies }\end{array}$ \\
\hline & & & & & $\begin{array}{c}\text { Septoria leaf } \\
\text { blotch }\end{array}$ & $\begin{array}{l}\text { Powdery } \\
\text { mildew }\end{array}$ & Yellow rust & Brown rust & \multicolumn{2}{|c|}{ powdery mildew } \\
\hline T. tauschii $(4 \mathrm{x})$ & T6 (DDDD) & 28 & - & 14 & 5 & 20 & 30 & 20 & 50 & 18.4 \\
\hline A. cristatum (4x) & Ac (PPPP) & 28 & 28 & - & 0 & 0 & 0 & 0 & 0 & 0 \\
\hline$\times$ Agroticum & T6Ac (DDPP) & 29 & 14 & 15 & 0 & 0 & 0 & 0 & 0 & 0 \\
\hline T. turgidum & Cv. Gerardo (=T15) & 28 & - & - & 30 & 10 & 10 & 10 & 10 & 3.7 \\
\hline T. turgidum & T89 "89 ICARDA" & 28 & - & - & 10 & 30 & 10 & 5 & 30 & 3.1 \\
\hline T. turgidum & Cv. Simeto & 28 & - & - & 20 & 20 & 10 & 20 & 30 & 5.8 \\
\hline "check & Cv. Vitrón & - & - & - & 40 & 20 & - & 20 & - & - \\
\hline "check & Cv. Tango & - & - & - & 20 & - & - & 40 & - & - \\
\hline "check & Cv. Arcobaleno & - & - & - & - & 30 & - & - & - & - \\
\hline T. aestivum check & Cv. Morocco & - & - & - & - & - & 40 & - & - & - \\
\hline T. aestivum check & Cv. Mahissa & - & - & - & - & - & 40 & - & - & - \\
\hline Backcross & {$[(\mathrm{T} 15 \times \mathrm{DDPP}) \times \mathrm{T} 15-1] \times \mathrm{T} 15-1$} & 41 & 6 & 7 & 0 & 0 & 0 & 5 & 0 & 0 \\
\hline$"$ & {$[(\mathrm{~T} 15 \times \mathrm{DDPP}) \times \mathrm{T} 15-1] \times \mathrm{T} 89-2$} & 40 & 6 & 6 & 0 & 0 & 0 & 0 & 0 & 0 \\
\hline$"$ & {$[(\mathrm{~T} 15 \times \mathrm{DDPP}) \times \mathrm{T} 15-4] \times$ Simeto- 1} & 40 & 6 & 6 & 0 & 0 & 0 & 0 & 0 & 0 \\
\hline$"$ & {$[(\mathrm{~T} 15 \times \mathrm{DDPP}) \times \mathrm{T} 15-4] \times$ Simeto- 2} & 42 & 7 & 7 & 0 & 0 & 0 & 0 & 0 & 0 \\
\hline$"$ & {$[(\mathrm{~T} 15 \times \mathrm{DDPP}) \times \mathrm{T} 15-5] \times \mathrm{T} 15-1$} & 32 & 2 & - & 0 & 0 & 0 & 5 & 0 & 0 \\
\hline “ & {$[(\mathrm{T} 15 \times \mathrm{DDPP}) \times \mathrm{T} 15-5] \times \mathrm{T} 15-3$} & - & 2 & - & 0 & 0 & 5 & 5 & 0 & 0 \\
\hline “ & {$[(\mathrm{T} 15 \times \mathrm{DDPP}) \times \mathrm{T} 15-5] \times \mathrm{T} 89-2$} & 34 & 4 & 2 & 0 & 0 & 0 & 10 & 0 & 0 \\
\hline
\end{tabular}

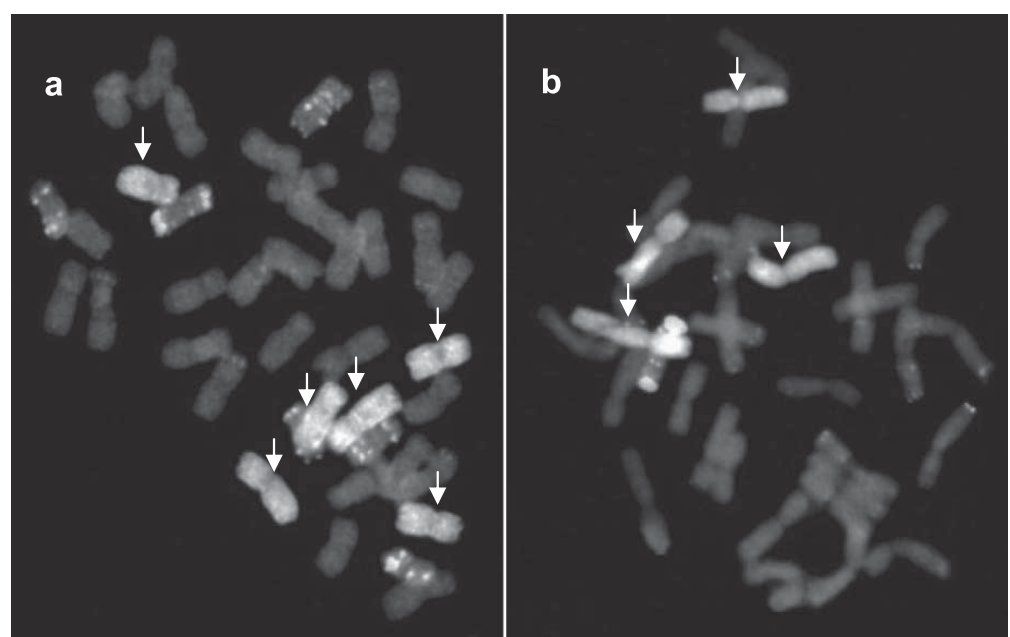

Fig. 1. FISH on root-tip chromosome preparations from two different cells at the mitotic metaphase. a) Cell of the plant $[(\mathrm{T} 15 \times \mathrm{DDPP}) \times \mathrm{T} 15-1] \times \mathrm{T} 89-2$ showing 6 chromosomes derived from A. cristatum (arrows), 6 chromosomes derived from $T$. tauschii and 28 chromosomes derived from T. turgidum. b) Cell with total genomic DNA probe from $A$. cristatum of the plant $[(\mathrm{T} 15 \times \mathrm{DDPP}) \times \mathrm{T} 15-5] \times \mathrm{T} 89-2$ harboring 4 chromosomes derived from A. cristatum. 
Figure 1 shows the FISH result of the somatic metaphase spreads of two hybrid plants carrying 6 (Fig. 1a) and 4 (Fig. 1b) P genome chromosomes from $A$. cristatum, respectively.

The $A$. cristatum accession used as parental line was resistant to wheat yellow rust (Puccinia striiformis f.sp. tritici), brown rust $(P$. triticina), septoria leaf blotch (Septoria tritici) and powdery mildew (Blumeria graminis f.sp. tritici) (Table 1).

\section{Reaction to septoria leaf blotch (Septoria tritici)}

Table 1 shows the reaction of the backcross derivatives $\left(\mathrm{BC}_{2}\right)$ and their parents to Septoria tritici. Both the amphiploid DDPP and A. cristatum were immune, while $T$. tauschii was highly resistant, with only $5 \%$ of the leaf area covered with lesions. All the durum wheat parents were susceptible, with the percentage of the leaf area covered with pycnidia ranging from $10 \%$ to $30 \%$. Infection on the durum wheat checks cvs. Vitron and Tango showed a high level and was uniform across the plot, with DS values 40 and $20 \%$, respectively. All the backcross derivatives were immune to the infection.

\section{Reaction to wheat yellow rust}

Infection on the bread wheat checks cvs. Morocco and Mahissa showed a high level and was uniform across the plot, with a DS value of $40 \%$. Tetraploid T. tauschii was highly susceptible, with $30 \%$ of the leaf area covered with pustules. Both the durum wheat parents and A. cristatum were moderately resistant with a disease severity of only $10 \%$. However, the hybrid plants were immune to the infection, except for one of the plants which showed a low $(5 \%)$ level of infection (Table 1).

\section{Reaction to brown rust}

Infection on the durum wheat checks cvs. Vitron and Tango showed a high level and was uniform across the plot, with DS values of 20 and $40 \%$, respectively. Both the amphiploid $\times$ Agroticum and $A$. cristatum individuals were immune to $P$. triticina, while $T$. tauschii was susceptible, with $20 \%$ of the leaf area covered with pustules. The durum wheat parents showed reaction ranging from resistance (T89, 5\%) to susceptibility (Simeto, 20\%). Three BC derivatives were immune to the infection $(0 \%)$, while other four were moderately resistant (5-10\%), with levels of disease similar to those of the resistant durum wheat parental lines T15 and T89.

\section{Reaction to wheat powdery mildew}

Both the amphiploid $\times$ Agroticum and its A. cristatum parent were immune to the infection with powdery mildew under field condition, while T. tauschii and the durum wheat lines were susceptible (DS values ranging from 10 to $30 \%$ ). Infection on the durum wheat checks cvs. Vitron and Arcobaleno showed a high level and was uniform across the plot, with average DS values of 20 and $30 \%$, respectively.
All the backcross derivatives to durum wheat were immune. To determine which of the donor parents was the source of resistance, the percentage of the leaf area covered with lesions and the percentage of established colonies were recorded in leaf segments of the backcross derivatives $\left(\mathrm{BC}_{2}\right)$ and their parents. T. tauschii and all the durum wheat parents were highly susceptible, whereas both the amphiploide DDPP and $A$. cristatum were immune (Table 1). Furthermore, the percentage of established colonies was similar (Table 1). In summary, all the seven backcross derivatives were immune to Blumeria graminis f.sp. tritici both under field and controlled conditions, with $A$. cristatum being the source of resistance.

In spite of the reduction and variation in the chromosome number of $A$. cristatum during the backcrossing process, a level of resistance similar to that of the $\times$ Agroticum parent was maintained in the backcross derivative plants that carried only two $A$. cristatum chromosomes, suggesting that one or both of these $A$. cristatum chromosomes harbored resistance genes.

The lack of homoeologous pairing between $A$. cristatum and wheat chromosomes (Martín et al. 1999, Soliman et al. 2001) represents a handicap for the incorporation of A. cristatum genes into the wheat genomes. However, the material developed in the present study offers the possibility to obtain $A$. cristatum chromosome addition and substitution lines in durum wheat, making the disease resistance gene from $A$. cristatum accessible for durum wheat breeding purposes as well as enabling to determine the chromosomal and genic relationships of the resistances.

The material developed represents a valuable germplasm for providing resistance to major diseases in durum wheat. Further approaches for developing resistant durum wheat lines are in progress by crossing the material obtained in the present study with durum wheat to reduce the number of both P- and D-genome chromosomes, coupled with a low or immune disease reaction.

\section{Acknowledgements}

The authors gratefully acknowledge the Spanish C.I.C.Y.T. proj. AGF99-1036-CO2-01-02 for the financial support. M.H. Soliman thanks the A.E.C.I for providing his PhD scholarship.

\section{Literature Cited}

Asay,K.H. and D.A.Johnson (1990) Genetic variance for forage yield in crested wheatgrass at six levels of irrigation. Crop Sci. 30: 79-82.

Cabrera,A., M.C.Ramírez and A.Martín (1999) Application of Cbanding and fluorescence in situ hybridization for the identification of the trisomics of Hordeum chilense. Euphytica 109: 123-129.

Chartrain,L., P.A.Brading, J.P.Widdowson and J.K.M.Brown (2004) Partial resistance to septoria tritici blotch (Mycosphaerella graminicola) in wheat cultivars Arina and Riband. Phyto- 
pathology 94: 497-504.

Chen,Q., J.Jahier and Y.Cauderon (1989) Production and cytogenetical studies of hybrids between Triticum aestivum L. Thell. and Agropyron cristatum (L.) Gaertn. C. R. Acad. Sci. Ser. 3, 308: 425-430.

Chen,Q., J.Jahier and Y.Cauderon (1992) Production and cytogenetic analysis of $\mathrm{BC}_{1}, \mathrm{BC}_{2}$ and $\mathrm{BC}_{3}$ progenies of an intergeneric hybrid between Triticum aestivum (L.) Thell. and tetraploid Agropyron cristatum (L.) Gaertn. Theor. Appl. Genet. 94: 698703.

Dewey,D.R. (1984) The genomic system of classification as a guide to intergeneric hybridization with the perennial Triticeae. In "Gene manipulation in plant improvement. 16th Stadler Genet. Symp." Gustafson,J.P. (ed.), Plenum, New York. p. 209-279.

Li,L.H. and Y.S.Dong (1990) Production and study of intergeneric hybrids between Triticum aestivum and Agropyron desertorum. Sci. China Ser. B Chem. Life Sci. \& Earth Sci. 5: 492-496.

Li,L.H. and Y.S. Dong (1991) Hybridization between Triticum aestivum L. and Agropyron michnoi Roshev. 1. Production and cytogenetic study of $F_{1}$ hybrids. Theor. Appl. Genet. 81: 312-316.

Limin,A.E. and D.B.Fowler (1987) Cold hardiness of forage grasses grown on the Canadian prairies. Can. J. Plant Sci. 67: 11111115 .

Limin, A.E. and D.B. Fowler (1990) An interspecific hybrid and amphiploid produced from Triticum aestivum crosses with Agropyron cristatum and Agropyron desertorum. Genome 33: 581-584.

Martín,A., A.Cabrera, E.Esteban, P.Hernández, M.C.Ramírez and D. Rubiales (1999) A fertile amphiploid between diploid wheat (Triticum tauschii) and crested wheatgrass (Agropyron cristatum). Genome 42: 519-524.

McIntosh,R.A., G.E.Hart, K.M.Devos, M.D.Gale and W.J.Rogers (1998) Catalogue of gene symbols for wheat. In "Proceedings of the 9th International Wheat Genetics Symp. Vol. 5." University Extension Press, University of Saskatchawan, Saskatoon, Canada. p. 267-269.

Rayburn, A.L. and B.S.Gill (1986) Isolation of D-genome specific repeated DNA sequence from Aegilops squarrosa. Plant Mol. Biol. Rep. 4: 102-109.

Rubiales,D. and T.L.W.Carver (2000) Defence reaction of Hordeum chilense accessions to three form species of cereal powdery mildew fungi. Can. J. Bot. 78: 1561-1570.

Scharen,A.L. (1999) Biology of the Septoria/Stagonospora pathogens: an overview. In "Septoria and Stagonospora diseases of cereals: a compilation of global research" Van Ginkel, M., A.McNab and J.Krupinsky (eds.), CIMMYT, Mexico DF. p. 19-22.

Sharma,H., H.Ohm, L.Goulart, R.Lister, R.Appels and O.Benlhabib (1995) Introgression and characterization of barley yellow dwarf virus resistance from Thinopyrum intermedium into wheat. Genome 38: 406-413.

Soliman,M.H., D.Rubiales and A.Cabrera (2001) A fertile amphiploid between durum wheat (Triticum turgidum) and the $\mathrm{x}$ Agroticum amphiploid (Agropyron cristatum $\times$ T. tauschii). Hereditas 135: 183-186.

Yahyaoui,A., S.Hakim, M.Al-Naimi and M.M.Nachit (2000) Multiple resistance in durum wheat (Triticum turgidum L. var. durum). In "Durum wheat improvement in the Mediterranean region: new challenges" Royo,C., M.M.Nachit, N.DiFonzo and J.L. Araus (eds.), CIHEAM, Zaragoza, Séminaires Méditerranéens, No. 40, Options méditerranéennes, p. 387-392. 